\title{
A New Test Method for Rating Materials as Noncombustible
}

\author{
Ronald L. Alpert and Mohammed M. Khan \\ FM Global Research \\ Norwood, MA 02062-9102, USA
}

\begin{abstract}
Several test methods commonly employed to rate the combustibility of materials are evaluated and compared to criteria for the stability of flaming combustion in the firescience literature. These science-based criteria are then used to analyze measurements and visual observations obtained when four prototype "noncombustible" materials are tested in the Fire Propagation Apparatus (ASTM E 2058). Based on this analysis, it is proposed that observation of the presence of flame and measurement of heat release rate at an applied heat flux of $50 \mathrm{~kW} / \mathrm{m}^{2}$ and an inflow oxygen concentration of $40 \%$ can be used to determine whether a material should be rated as "noncombustible."
\end{abstract}

KEY WORDS: rating of combustibility, non-combustible materials, heat of combustion INTRODUCTION

The problem of how to rate the combustibility of components of building products that contain small amounts of fuel has been an important issue for code officials and standards developers for many decades. The building industry and its customers and regulators want to be able to classify commonly used building products as "noncombustible" when they contain such small amounts of fuel in an inert matrix that the materials are considered not to be a hazard. To study this problem, current test methods for combustibility have been evaluated, combustibility criteria have been examined conceptually and tests have been performed to explore the practicality of combustibility measurements. Science-based criteria are then used to analyze test results for selected prototype product components that most observers would classify as having negligible combustibility.

The scientific criterion that is proposed in this study for rating combustibility is whether the product component can itself support flaming combustion, i.e., whether the component can burn with an attached flame when its surface is exposed to a typical fire environment. Such a component can certainly still contribute fuel to a fire involving other materials but at least application of this criterion provides an objective basis for assigning a combustibility designation.

\section{EXISTING COMBUSTIBILITY TEST METHODS}

Currently employed test methods for combustibility use the heat of combustion from a bomb calorimeter-type apparatus (ASTM D 5865 [1] similar to ISO 1716 [2]) and/or the temperature increase of a specimen in a furnace apparatus (e.g., ASTM E 136 [3] and ISO $1182[4])$.

The heat of combustion per unit mass of virgin material or per unit mass of material vapors generated does not appear to be a reasonable basis for a combustibility rating. 
One problem with the use of heat of combustion per unit mass of the virgin material is that this quantity has no fundamental significance as far as flaming combustion is concerned. Very small heat of combustion values can result from high "inert" or "residue" content but that doesn't guarantee "noncombustibility." While heat of combustion per unit mass of material vapors generated, $\left(\Delta H_{c}\right)_{\text {vapors }}$, does have fundamental significance, the difficulty in finding a reasonable lower limit on this parameter to prevent flaming combustion is discussed below. In addition, for materials containing sulfur, nitrogen, fluorine, silicon or phosphorus, the exact composition of the final products of reaction, and the resultant heat of combustion magnitude, is highly scenario dependent.

The ASTM E 136 [3] and ISO 1182 [4] furnace tests for non-combustibility rely on the use of a specified furnace temperature and environment and an arbitrary temperature rise in thermocouples within or on a 50-mm high specimen. Ahonen [5] has demonstrated that, due to the complex heat exchange involving the thermocouples, the oven interior and the instrumented specimen, even small changes in thermal contact resistance due to specimen expansion or shrinkage can be mistaken for combustion effects in materials with a high inert content. Such arbitrary factors eliminate any theoretical basis for generalizing results to other than the furnace situation. Hence, it would be difficult to predict theoretically from furnace tests what would happen under realistic fire conditions, especially for materials that are not homogeneous. It is preferable to expose a material to a controlled, specified heat flux simulating a fire environment. In conclusion, the temperature rise of a specimen in a furnace is too dependent on the exact furnace scenario to extract general information for use in rating combustibility.

Both the bomb calorimeter technique and the furnace test method are unable to handle composite materials or inhomogeneous products adequately due to the need for producing a small, well-mixed specimen representative of the real product. On the other hand, modern laboratory calorimeters can be used to determine if a full-scale product component cannot anchor a flame under conditions that promote combustion and simulate the heat flux environment in real-scale fires.

\section{ANALYSIS OF COMBUSTIBILITY CRITERIA}

\section{Heat of Combustion}

It is proposed that a material be rated as "noncombustible" if that material cannot support flaming combustion, i.e., cannot anchor a diffusion flame. In order for such a diffusion flame to exist, a minimum average gas temperature rise, $\Delta T_{f l}$, must be established. Note that conditions for the existence of the flame alone in the presence of fuel vapors and an oxidant are being analyzed, not the energy required to produce those fuel vapors. The latter includes the energy needed to raise the temperature of the fuel and inert components to a vaporization temperature as well as the heat of vaporization at that temperature.

Energy conservation for the steady mass flow of fuel vapor, $\dot{m}_{f}$, and air into the flame at ambient temperature and the mass flow of hot combustion products (equal to the inflow of fuel and air) out of the flame yields: 


$$
\left(\Delta H_{c}\right)_{\text {vapors }} \dot{m}_{f} \approx\left(\dot{m}_{f}+\dot{m}_{\text {air }}\right) c_{p} \Delta T_{f l}+\chi_{R} \dot{m}_{f}\left(\Delta H_{c}\right)_{\text {vapors }}
$$

where $\chi_{R}$ is the fraction of the total heat released that is lost by radiation and the specific heat of fuel vapor is assumed to be that of air. Therefore,

$$
\left(\Delta H_{c}\right)_{\text {vapors }} \approx \frac{\left(1+\frac{\dot{m}_{\text {air }}}{\dot{m}_{f}}\right)}{1-\chi_{R}} c_{p} \Delta T_{f l}
$$

The minimum value for the heat of combustion to sustain the flame is obtained from Eq. 2 by considering two situations, one for non-luminous flames with low radiant heat losses $\left(\chi_{R} \approx 0.1\right.$ ) and the other for luminous flames $\left(\chi_{R} \approx 0.3\right.$ to 0.4$)$. Non-luminous, buoyant diffusion flames are known [6] to have an average temperature of 1200 to 1300 ${ }^{\circ} \mathrm{C}$ (assume $\Delta T_{f l}=1250{ }^{\circ} \mathrm{C}-20{ }^{\circ} \mathrm{C}=1230 \mathrm{~K}$ and $\chi_{R}=0.12$ ) while the corresponding luminous flames [6] have average temperatures of 900 to $1000{ }^{\circ} \mathrm{C}$ (assume $\Delta T_{f l}=930 \mathrm{~K}$ and $\left.\chi_{R}=0.35\right)$. Substitution of corresponding values for $\Delta T_{f l}$ and $\chi_{R}$ as well as the specific heat, $\mathrm{c}_{\mathrm{p}}$, of air $(0.001 \mathrm{~kJ} / \mathrm{g} \mathrm{K})$ into Eq. 2 then yields:

$$
\left(\Delta H_{c}\right)_{\text {vapors }} \approx 1.4\left(1+\frac{\dot{m}_{\text {air }}}{\dot{m}_{f}}\right) \mathrm{kJ} / \mathrm{g}
$$

Equation 3 is valid both for the luminous and non-luminous flame parameter sets noted above. The stoichiometric mass ratio of air to fuel in Eq. 3 is about one-third the net heat of complete combustion per unit mass of fuel consumed, $\Delta H_{T}$, when the latter is expressed in $[\mathrm{kJ} / \mathrm{g}]$. This is derived from the fact that the net heat of complete combustion per unit mass of oxygen consumed, $\Delta H_{O}^{*}$, is nearly a constant, equal to 13 $\mathrm{kJ} / \mathrm{g}$. By using values for $\Delta H_{T}$ and $\Delta H_{O}^{*}$ tabulated [7] for a number of common polymers, it is found that the stoichiometric mass ratio of air to fuel is typically at least 5 for these compounds. The minimum heat of combustion of fuel vapors for a flame to exist is thus given by:

$$
\left(\Delta H_{c}\right)_{\text {vapors }}^{\min } \approx 1.4(1+5) \approx 8.4 \mathrm{~kJ} / \mathrm{g}
$$

Unfortunately, Eq. 4 is not valid when high molecular weight fuels have very low oxygen requirements or fuel vapors have a reduced specific heat. For example, highly fluorinated compounds have heats of combustion as low as 4 to $5 \mathrm{~kJ} / \mathrm{g}$ and these materials are certainly all combustible. Thus, it is very difficult to establish a combustibility criterion on the basis of the heat of combustion of fuel vapors and even more difficult to predict combustibility from the heat of combustion of the virgin material.

For materials that consist of inert compounds (residue) mixed with vaporizable fuel, the total heat of combustion per unit mass of virgin material will generally be less than the heat of combustion of the fuel vapors alone, as shown by the following equation:

$$
\left(\Delta H_{c}\right)_{\text {virgin }}=\left(\Delta H_{c}\right)_{\text {residue }} \times Y_{\text {residue }}+\left(\Delta H_{c}\right)_{\text {vapors }} \times\left(1-Y_{\text {residue }}\right)
$$


where the subscript "residue" refers to the mass fraction of residue in the virgin material that remains after burning or after a muffle furnace procedure, such as ASTM D 5630 [8] (where a 30-minute test duration and temperatures of 800 or $900{ }^{\circ} \mathrm{C}$, depending on polymer composition, are specified). If the residue is inert, then the residue heat of combustion is zero. For substantial residue fractions, the heat of combustion of the virgin material can thus be very different from that of the vapors. This difference can lead to confusion if the heat of combustion is not carefully defined.

\section{Fuel Mass Flow Rate per Unit Exposed Surface Area}

Various studies [9] have confirmed that a critical fuel mass flow rate per unit area (mass flux), $\dot{m}_{f}^{\prime \prime}$, is required to sustain flaming combustion. Below this mass flux of fuel vapor, which is in the range of 4 to $6 \mathrm{~g} / \mathrm{m}^{2} \mathrm{~s}$, flame extinction occurs for a wide range of heat flux, environmental (e.g., oxygen concentration) and fuel dilution conditions.

If a material contains nonvolatile inert compounds mixed with fuel, the fuel mass flux, under laboratory heating conditions simulating a fire, is simply the measured mass loss rate of the material per unit exposed surface area. This mass loss rate per unit area must therefore be greater than 4 to $6 \mathrm{~g} / \mathrm{m}^{2} \mathrm{~s}$ to sustain flaming combustion. However, when a material contains volatile, but inert, compounds (e.g., water bound chemically to a material component, as in gypsum) only a fraction of the measured mass loss will be fuel. In this case, it is impossible to determine easily if the critical fuel mass flux value is being exceeded. Hence, fuel mass flux is not a practical criterion for combustibility.

\section{Chemical Heat Release Rate per Unit Surface Area}

The heat release rate per unit exposed specimen surface area, $\dot{Q}_{c h}^{\prime \prime}$, is routinely measured in laboratory, bench-scale calorimeters. Critical heat release rate per unit area to sustain combustion can be obtained from experiments conducted by Wood et al. [10] and from work of Heskestad [11]. The former study shows that coherent flaming in a well-defined fire plume above a pool fire of effective diameter, D (based on equivalent area) requires the non-dimensional heat release rate parameter, $Q_{D}^{*}$, to be greater than one-tenth.

Below this value of $Q_{D}^{*}$, the fire plume breaks up into flamelets distributed above the pool surface. The requirement for flaming in a coherent plume is expressed in the following relation:

$$
Q_{D}^{*}=\frac{\dot{Q}_{c h}}{\rho_{\infty} C_{p} T_{\infty} D^{2} \sqrt{g D}}=\frac{\pi \dot{Q}_{c h}^{\prime \prime}}{4 \rho_{\infty} C_{p} T_{\infty} \sqrt{g D}} \geq 0.1
$$

This relation implies the following critical heat release rate at the transition from a welldefined fire plume to distributed flamelets:

$$
\left(\dot{Q}_{c h}^{\prime \prime}\right)_{c r i t}=141.5 \sqrt{D} \mathrm{~kW} / \mathrm{m}^{2}
$$

The work of Heskestad [11] indicates that the distributed flamelets noted above will not anchor to the surface of the fuel, but instead produce an unstable flame pattern with significant non-flaming areas, when the non-dimensional heat release rate parameter is reduced to: 


$$
Q_{D}^{*}=\frac{\dot{Q}_{c h}}{\rho_{\infty} C_{p} T_{\infty} D^{2} \sqrt{g D}}=\frac{\pi \dot{Q}_{c h}^{\prime \prime}}{4 \rho_{\infty} C_{p} T_{\infty} \sqrt{g D}}=0.037
$$

This condition, which Heskestad [11] interprets as equivalent to a lean flammability limit, becomes the following in terms of the critical heat release rate required for a sharp drop in flame coverage over a flat, continuous fuel:

$$
\left(\dot{Q}_{c h}^{\prime \prime}\right)_{c r i t}=53 \sqrt{D} \mathrm{~kW} / \mathrm{m}^{2}
$$

For a fuel length-scale, D, comparable to one-meter, Eq. 9 implies that sustained flaming will only be possible in normal air if the heat release rate per unit area is greater than about $53 \mathrm{~kW} / \mathrm{m}^{2}$. Experience [7] has shown that materials exhibit values of $\dot{Q}_{c h}^{\prime \prime}$ greater than about $75 \mathrm{~kW} / \mathrm{m}^{2}$ while undergoing flaming combustion in simulated $0.1-\mathrm{m}$ diameter pool-fire scenarios (i.e., an external, or exposure heat flux of $50 \mathrm{~kW} / \mathrm{m}^{2}$ ).

\section{Promotion of Flaming Combustion}

Because the term "noncombustible" is defined here as "not capable of anchoring a flame", if sustained flaming cannot be observed in a realistic fire environment, then the material should surely be rated as "noncombustible." A realistic fire environment can be simulated on a small-scale in the Fire Propagation Apparatus (FPA) [12] when an external heat flux of $50 \mathrm{~kW} / \mathrm{m}^{2}$ is applied to a horizontal, $100-\mathrm{mm}$-scale specimen during a heat-release-rate measurement in normal air. An imposed heat flux of this magnitude simulates the asymptotic total flame heat flux (see reference [7]) within pool fires of common polymers and gasoline-like liquids as pool diameter increases above 1 or $2 \mathrm{~m}$.

Even with this $50-\mathrm{kW} / \mathrm{m}^{2}$-heat flux, the small scale of this test environment may not allow some combustible materials to ignite consistently, e.g., fuels that have a high halogen composition or other fire-retardant compounds. To insure that ignition of combustible materials will be prompt even at a small-scale, a heat flux of 75 or 100 $\mathrm{kW} / \mathrm{m}^{2}$ in normal air can be imposed or an air inflow containing $40 \%$ oxygen can be used. FPA tests performed in the latter, $40 \%$ oxygen environment to simulate the asymptotic flame heat flux behavior [13] of large pool fires invariably lead to prompt ignition for a wide range of combustible materials. A combination of both the $50 \mathrm{~kW} / \mathrm{m}^{2}$ imposed heat flux and the $40 \%$ oxygen environment is chosen here to promote flaming combustion.

A study described recently by Gandhi [14] provides additional evidence of the need for a $40 \%$ oxygen environment when conducting small-scale tests. This study of highly fire resistant (but still combustible) materials with the Cone Calorimeter [15] shows that, in normal air, the specimens exhibit irregular burning behavior and do not undergo sustained steady flaming combustion. If sustained flaming also cannot be observed in a $40 \%$ oxygen environment, it may be a clear indication of noncombustible behavior.

\section{EXPERIMENTS}

To investigate whether a combustibility criterion based on measurement of heat release rate is practical, four prototype "noncombustible" product components have been tested in the horizontal configuration in the FPA: expanded, low-density glass, glass fiber and two brands of mineral wool. These materials, which are core components of commercial, metal-clad panels, satisfy the requirements of ASTM E 136 [3] (similar to ISO 1182 [4]). 
The prototype components also have heats of combustion by the bomb calorimeter method (ASTM D 5865 [1] similar to ISO 1716 [2]) sufficiently low to qualify potentially (note, there are other requirements) for the "A1" rating [16] under PrEN 13501-1. The panel core specimens and test conditions are described in Table 1, while Table 2 provides the bomb calorimeter data corresponding to each material. For Materials No. 2, 3 and 4 in Table 1, the original product components have been reduced in thickness to remove contamination from the polymer glue that bonds the metal facing to the core material. As indicated in Table 1, tests are conducted in the FPA at two external heat fluxes and at both normal and elevated ambient oxygen concentrations in air. Control of ambient oxygen is easily achieved in the FPA because the specimen is within a 162-mm ID quartz pipe containing an oxygen/air flow of $0.0033 \mathrm{~m}^{3} / \mathrm{s}$.

Table 1. Overview of Combustion Test Experiments in the FPA

\begin{tabular}{|l|c|c|c|c|}
\hline $\begin{array}{c}\text { Material No. and } \\
\text { Type of Product }\end{array}$ & $\begin{array}{c}\text { Core } \\
\text { Thickness }\end{array}$ & $\begin{array}{c}\text { Core } \\
\text { Density }\end{array}$ & $\begin{array}{c}\text { External } \\
\text { Heat Flux }\end{array}$ & $\begin{array}{c}\text { Ambient } \\
\text { Oxygen } \\
\text { Concentration } \\
\text { [Vol. \%] }\end{array}$ \\
\hline 1. Expanded Glass & 46.5 & 113 & 40 & 21 \\
& & & 50 & 21 \\
& & & 50 & 40 \\
\hline 2. Mineral Wool & 25.4 & 120 & 50 & 40 \\
& & & 40 & 21 \\
\hline 3. Mineral Wool & 50.8 & 117 & 50 & 21 \\
& & & 50 & 40 \\
& & & 40 & 21 \\
\hline 4. Glass Fiber & 50.8 & 87 & 50 & 40 \\
& & & 40 & 21 \\
\hline
\end{tabular}

Table 2 provides the heats of combustion of the virgin materials and the fuel vapors alone. The latter is calculated from Eq. 5 using the bomb calorimeter value for a single specimen of the virgin material (with no benzoic acid) and the residue mass fraction measured from a muffle furnace test. Except for Material No. 1, the fuel vapor heats of combustion are all well above the value required (see Eq. 4) to sustain flaming combustion.

Table 2. Bomb Calorimeter Data for Panel Core Materials

\begin{tabular}{|c|c|c|c|}
\hline $\begin{array}{c}\text { Material No. } \\
\text { and Type of } \\
\text { Product }\end{array}$ & $\begin{array}{c}\left(\Delta H_{c}\right)_{\text {virgin }} \text { from } \\
\text { Bomb Calorimeter } \\
{[\mathbf{k J} / \mathbf{g}]}\end{array}$ & $\begin{array}{c}\text { Residue from } \\
\text { Furnace Test } \\
{[\%]}\end{array}$ & $\begin{array}{c}\left(\Delta H_{c}\right)_{\text {vapors }} \text { from }_{\text {Eq. 5 }}^{\mathbf{~}} \\
{[\mathbf{k J} / \mathbf{g}]^{\mathbf{a}}}\end{array}$ \\
\hline $\begin{array}{c}\text { 1. Expanded } \\
\text { Glass }\end{array}$ & 0 & 99.7 & 0 \\
\hline $\begin{array}{c}\text { 2. Mineral } \\
\text { Wool }\end{array}$ & 1.5 & 96.2 & 39.5 \\
\hline $\begin{array}{c}\text { 3. Mineral } \\
\text { Wool }\end{array}$ & 1.1 & 96 & 27.5 \\
\hline 4. Glass Fiber & 1.8 & 93 & 25.7 \\
\hline
\end{tabular}


${ }^{a}$ Calculation assumes residue from the muffle furnace test has zero heat of combustion. Heat release rate measurements in the FPA are performed with horizontal, 96.52-mm diameter specimens $\left(0.00732 \mathrm{~m}^{2}\right.$ exposed surface area) sealed in $0.05-\mathrm{mm}$ thick aluminum foil and then mounted in well-insulated holders [17] consisting of 4 layers of 3-mm thick Cotronics ceramic paper. The top exposed surface of each specimen is flush with the top of the ceramic insulation. Following the procedure in ASTM E 2058, a premixed, 10-mm long ethylene-oxygen pilot flame is positioned about 10-mm above and within the periphery of this top surface to insure prompt ignition if sufficient fuel vapors are present. Note that heat release and mass loss rate data are obtained at one-second intervals until there is no measured mass loss or until vapors are no longer observed.

\section{RESULTS AND DISCUSSION}

In spite of the continuous pilot, flames are not observed with any of the four materials, even when the combustion air is enriched to $40 \%$ oxygen and a $50 \mathrm{~kW} / \mathrm{m}^{2}$ external heat flux is applied to simulate a realistic fire environment.

Figure 1 contains heat release rate $(\mathrm{HRR}=\dot{Q})$ and mass loss rate results for Material No. 3 , mineral wool. During the 10-minute duration of this particular test, in addition to the mass loss (generation of vapor) rate induced by the external heat flux, generation rates of $\mathrm{CO}_{2}$ and $\mathrm{CO}$ gas species are measured, along with the depletion of oxygen in the product stream. Heat release rates computed from the $\mathrm{CO}_{2}$ and $\mathrm{CO}$ generation rates are shown in Figure 1 to have very similar profiles for the two different applied heat fluxes and the two oxygen concentrations. The heat release rates based on carbon oxide formation and oxygen depletion are calculated from the following respective expressions:

$$
\dot{Q}=1.33 \times 10^{4}\left(\dot{G}_{\mathrm{CO}_{2}}-\dot{G}_{\mathrm{CO}_{2}}^{0}\right)+1.11 \times 10^{4}\left(\dot{G}_{\mathrm{CO}}-\dot{G}_{\mathrm{CO}}^{0}\right)
$$

and,

$$
\dot{Q}=1.3 \times 10^{4} \dot{D}_{O_{2}}
$$

where $\dot{G}_{\mathrm{CO}_{2}}$ and $\dot{G}_{\mathrm{CO}}[\mathrm{kg} / \mathrm{s}]$ are the generation rates of $\mathrm{CO}_{2}$ and of $\mathrm{CO}$, respectively ( $\dot{G}_{\mathrm{CO}_{2}}^{0}$ and $\dot{G}_{\mathrm{CO}}^{0}$ are values prior to ignition) and where $\dot{D}_{\mathrm{O}_{2}}[\mathrm{~kg} / \mathrm{s}]$ is the consumption rate of oxygen resulting from combustion. The coefficients in Eq. 10 and 11 are average values obtained in reference [7] through analysis of more than 20 different classes of solids, liquids and gases. Average values are used here in the absence of information on the exact composition of the combustible components of the prototype materials.

At an inlet oxygen concentration of $40 \%$, the peak HRR nearly doubles from that at a $21 \%$ concentration, while increasing the applied heat flux from 40 to $50 \mathrm{~kW} / \mathrm{m}^{2}$ at $21 \%$ $\mathrm{O}_{2}$ concentration results in just a $14 \%$ increase in peak HRR. Mass loss rate profiles show trends similar to these HRR profiles. The generation rates of $\mathrm{CO}_{2} / \mathrm{CO}$ species used to calculate HRR are probably due to some type of glowing combustion reactions within the panel core materials. Such glowing reactions would be driven by diffusion of oxygen from the inlet air so doubling of the oxygen concentration would be expected to double the diffusion rate, and hence double the HRR, as is observed when ambient $\mathrm{O}_{2}$ increases from $21 \%$ to $40 \%$. Release of gaseous breakdown products containing $\mathrm{CO}_{2}$ and $\mathrm{CO}$ unrelated to combustion is possible but is very unlikely based on the oxygen consumption measurements to be discussed below. 
The 50-mm thickness for all the tested materials (except for the maximum available 25mm thickness of Material No. 2) insures that there is sufficient specimen to provide a reasonable time during which vapors are generated. The total vapor generation time is shown in Figure 1 to be about 200 seconds, which should be adequate to allow the observation of any flaming during a test in the FPA. However, this time interval usually includes spikes in heat generation lasting only several seconds, which means that it is especially important to measure heat release rate without excessive time averaging. Based on the data from the four prototype materials, it is estimated that heat release rate should be measured every second and averaged over a maximum of 10 or 15-seconds.
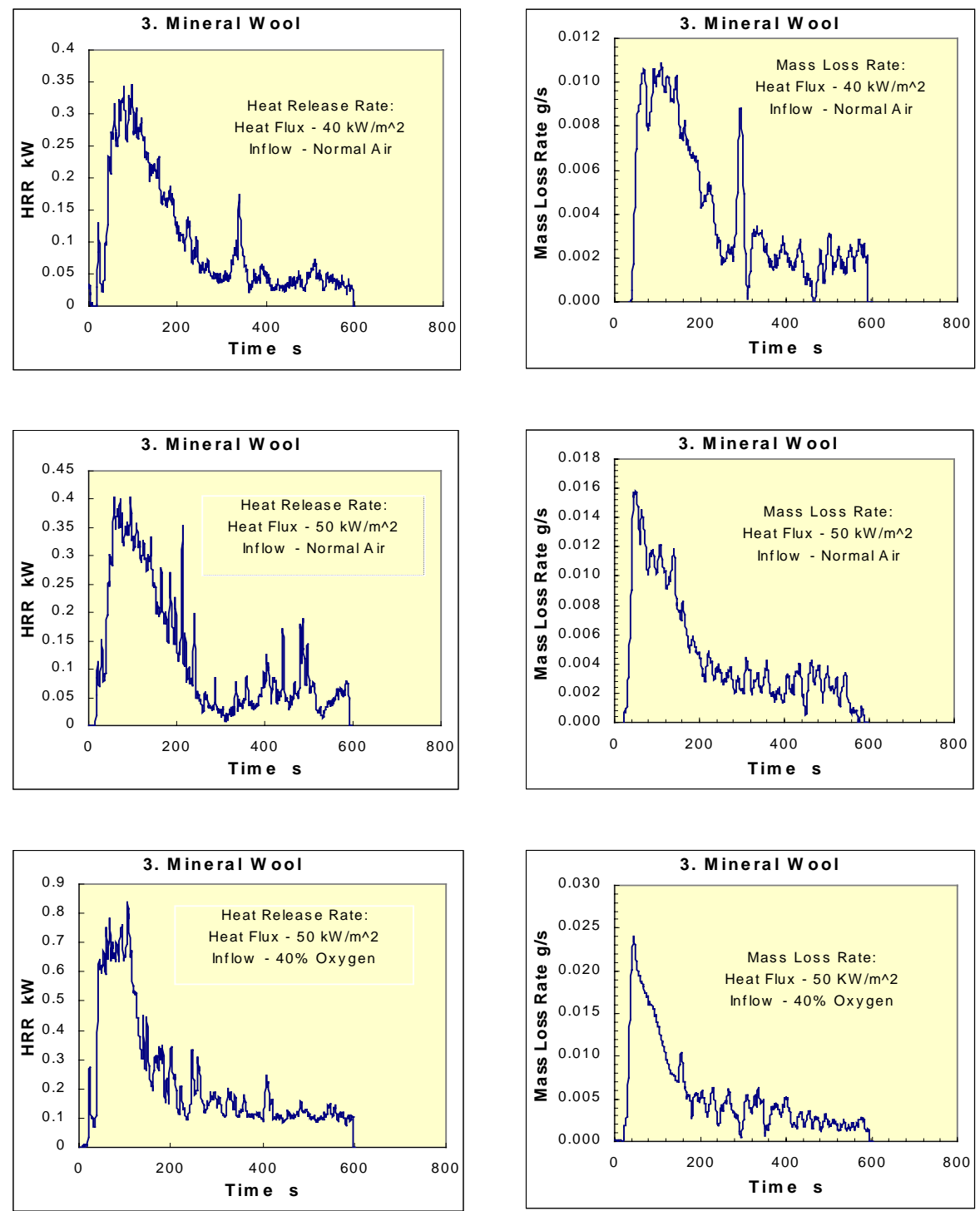
Figure 1. Typical Heat Release Rate and Mass Loss Rate Measurement Curves

Table 3 contains the heat release and mass loss measurement results from the (nonflaming) tests performed in the FPA. It can be seen that the maximum HRR measured from oxygen depletion is always comparable to or greater than that derived from the carbon dioxide generation rate. Hence, it is likely that $\mathrm{CO}_{2}$ generation is due to combustion (probably glowing surface) reactions and not due to release of $\mathrm{CO}_{2}$ from inert compounds during the heating process. The doubling of the HRR when oxygen concentration increases from 21 to $40 \%$ at a constant applied heat flux is evident for Materials 2, 3 and 4, confirming the existence of glowing combustion reactions discussed in connection with Figure 1.

Table 3. Heat Release and Mass Loss from Panel Core Materials in the FPA

\begin{tabular}{|c|c|c|c|c|c|c|c|}
\hline $\begin{array}{c}\text { Mat. } \\
\text { No. }\end{array}$ & $\begin{array}{c}\text { External } \\
\text { Heat } \\
\text { Flux } \\
{\left[\mathrm{kW} / \mathrm{m}^{2}\right]}\end{array}$ & $\begin{array}{c}\text { Ambient } \\
\text { Oxygen } \\
\text { [Vol. \%] }\end{array}$ & $\begin{array}{c}\begin{array}{c}\text { Max HRR } \\
\text { from } \mathrm{CO}_{2}\end{array} \\
{[\mathrm{~kW}]^{\mathrm{a}}}\end{array}$ & $\begin{array}{c}\text { Max HRR } \\
\text { from } \mathrm{O}_{2} \\
{[\mathrm{~kW}]^{\mathrm{a}}}\end{array}$ & $\begin{array}{c}\text { Max 19-s } \\
\text { Avg. } \dot{m}_{f} \\
{[\mathrm{~g} / \mathrm{s}]^{\mathbf{b}}}\end{array}$ & $\begin{array}{c}\text { Total Heat } \\
\text { from } \mathrm{CO}_{2} \\
{[\mathrm{~kJ}]}\end{array}$ & $\begin{array}{c}\text { Total } \\
\text { Mass Loss } \\
\\
{[\mathrm{g}]}\end{array}$ \\
\hline 1 & 40 & 21 & 0.405 & 0.393 & 0.029 & 6.02 & 1.69 \\
\hline 1 & 50 & 21 & 0.382 & 0.364 & 0.0481 & 3.59 & 0.71 \\
\hline 1 & 50 & 40 & 0.552 & N.A. & 0.0261 & 12.1 & 0.687 \\
\hline 2 & 40 & 21 & 0.367 & 0.47 & 0.0122 & 25.7 & 1.22 \\
\hline 2 & 50 & 40 & 0.766 & N.A. & 0.0629 & 51.6 & 3.24 \\
\hline 3 & 40 & 21 & 0.346 & 0.4 & 0.0109 & 20.9 & 0.817 \\
\hline 3 & 50 & 21 & 0.404 & 0.454 & 0.0158 & 36.8 & 1.67 \\
\hline 3 & 50 & 40 & 0.84 & N.A. & 0.0241 & 82.3 & 2.30 \\
\hline 4 & 40 & 21 & 0.371 & 0.468 & 0.0335 & 12.9 & 2.72 \\
\hline 4 & 50 & 40 & 0.78 & N.A. & 0.0954 & 88.4 & 5.00 \\
\hline
\end{tabular}

${ }^{a}$ Maximum heat release rate (HRR) is obtained from measurements of $\mathrm{CO}_{2}$ generation rate and from $\mathrm{O}_{2}$ depletion rate recorded every second for the total test time. The latter method is not used when $40 \% \mathrm{O}_{2}$ is supplied to the burning specimen (i.e., N.A.)

${ }^{\mathrm{b}}$ Mass loss rate of the specimen (flow rate of fuel vapors, $\dot{m}_{f}$, if only fuel vaporizes) is obtained by differentiating a running regression fit to mass loss data over a period of 19 seconds.

The measurement results that are provided in Table 3 are used to calculate critical parameters for analysis of combustibility in Table 4. For example, the heat of combustion of the fuel vapors in Table 4 is the ratio of the last two columns in Table 3.

Table 4 provides the residue percent (the mass fraction of the virgin specimen remaining at the end of a test) in a realistic fire environment, as simulated by the FPA. This quantity is the ratio of the final mass to the initial mass of each specimen measured postand pre-test, respectively, by a laboratory balance (whereas the total mass loss in Table 3 is obtained from the load-cell mass loss measurement). It can be seen that residue percentages from the muffle furnace procedure in Table 2 are consistently greater than those derived from lab balance measurements before and after tests in the FPA. 
The reason for the lower values of residue percentage for specimens exposed in the FPA is unknown, but perhaps the heating environment in the FPA causes somewhat more of the specimen to vaporize than in the muffle furnace. Use of a $40 \%$ oxygen environment appears to cause a significant reduction in the residue percentage only for Material No. 2.

The heat of combustion per unit mass of fuel vapors listed in Table 4 is generally well above the minimum required to have flaming combustion (see Eq. 4), especially when the combustion air contains $40 \%$ oxygen. All of these directly measured fuel vapor heat of combustion values are comparable to the values inferred from the bomb calorimeter and muffle furnace measurements through use of Eq. 5 (compare Table 2 and Table 4).

The nearly factor of 4 increase in the heat of combustion for Materials No. 1 and 4 in Table 4, as oxygen concentration increases from 21 to $40 \%$, is surprising. This increase may be caused by the fact that a glowing surface reaction is not fully established in normal air but does become well established at a higher oxygen concentration.

Table 4. Analysis of FPA Tests of Panel Core Materials

\begin{tabular}{|c|c|c|c|c|c|c|}
\hline $\begin{array}{c}\text { Mat. } \\
\text { No. }\end{array}$ & $\begin{array}{c}\text { External } \\
\text { Heat Flux } \\
{\left[\mathrm{kW} / \mathrm{m}^{2}\right]}\end{array}$ & $\begin{array}{c}\text { Ambient } \\
\text { Oxygen } \\
\text { [Vol. \%] }\end{array}$ & $\begin{array}{c}\text { Residue by } \\
\text { Lab } \\
\text { Balance[\%] }\end{array}$ & $\begin{array}{c}\left(\Delta H_{c}\right)_{\text {vapors }} \\
{[\mathbf{k} \mathbf{J} / \mathbf{g}]}\end{array}$ & $\begin{array}{c}\dot{Q}_{\max }^{\prime \prime} \\
{\left[\mathbf{k W} / \mathbf{m}^{2}\right]}\end{array}$ & $\begin{array}{c}\left(\dot{m}_{f}^{\prime \prime}\right)_{\max } \\
{\left[\mathbf{g} / \mathbf{m}^{2} \mathbf{s}\right]}\end{array}$ \\
\hline 1 & 40 & 21 & 95 & 3.56 & 55.4 & 3.97 \\
\hline 1 & 50 & 21 & 97 & 5.06 & 52.2 & 6.58 \\
\hline 1 & 50 & 40 & 97 & 17.6 & 75.5 & 3.57 \\
\hline 2 & 40 & 21 & 90 & 21.1 & 50.2 & 1.67 \\
\hline 2 & 50 & 40 & 85 & 15.9 & 104.7 & 8.60 \\
\hline 3 & 40 & 21 & 91 & 25.6 & 47.3 & 1.49 \\
\hline 3 & 50 & 21 & 94 & 22.0 & 55.2 & 2.16 \\
\hline 3 & 50 & 40 & 93 & 35.8 & 114.9 & 3.30 \\
\hline 4 & 40 & 21 & 86.7 & 4.76 & 50.7 & 4.58 \\
\hline 4 & 50 & 40 & 85 & 17.7 & 106.6 & 13.04 \\
\hline
\end{tabular}

The last two columns of Table 4 contain maximum HRR per unit surface area and the maximum fuel mass flux (assuming only fuel vaporizes) for all test conditions. As discussed before, the four prototype materials don't show any evidence of flaming but do exhibit a heat release rate, the maximum value of which roughly doubles when the oxygen concentration increases from 21 to $40 \%$. In normal air, the maximum (onesecond average) heat release rate of $55.4 \mathrm{~kW} / \mathrm{m}^{2}$ corresponds to the transition from full to partial flame coverage on a 1.1-m diameter specimen, based on the critical condition in Eq. 9. Hence, none of these materials would be able to support sustained flaming combustion at realistic length scales. Further confirmation that the materials should indeed be classified as non-combustible is derived from their behavior in a $40 \%$ oxygen environment, where sustained flaming is not observed and the maximum heat release rate compared to that in normal air is consistent with assumed surface/glowing reactions. Note that the maximum mass flux from Materials No. 1 and 3 also happens to be less than the value of pure fuel mass flux, 4 to $6 \mathrm{~g} / \mathrm{m}^{2} \mathrm{~s}$, required for sustained flaming. 
Table 5. Comparison of $\dot{Q}_{\max }^{\prime \prime}$ for Mineral Wool

\begin{tabular}{|c|c|c|}
\hline $\begin{array}{c}\text { Core Mineral- } \\
\text { Wool No. }\end{array}$ & $\begin{array}{c}\dot{Q}_{\max }^{\prime \prime} \\
(1-\mathrm{s} \text { average }) \\
{\left[\mathrm{kW} / \mathrm{m}^{2}\right]}\end{array}$ & $\begin{array}{c}\text { Maximum } \\
\text { Diameter for } \\
\text { Sustained } \\
\text { Flaming [m] }\end{array}$ \\
\hline 2 & 105 & 0.98 \\
\hline 3 & 115 & 1.2 \\
\hline 5 & 103 & 0.94 \\
\hline 6 & 133 & 1.6 \\
\hline 7 & 143 & 1.8 \\
\hline 8 & 146 & 1.9 \\
\hline
\end{tabular}

\section{APPLICATION TO MINERAL WOOL CORES OF METAL FACED PANELS}

In addition to the prototype materials (Material No. 2 and 3) discussed above, several different types of mineral wool core component materials have been tested in the FPA with an external heat flux of $50 \mathrm{~kW} / \mathrm{m}^{2}$ and an ambient oxygen concentration in air of $40 \%$. In no case has sustained flaming been observed, but a range of heat release rates per unit surface area has been measured (based on $\mathrm{CO}_{2}$ generation), as shown in Table 5.

Assuming that a $40 \%$ oxygen environment should lead to approximate doubling of heat release rate due to surface reactions, the critical condition given by Eq. 9 becomes:

$\left(\dot{Q}_{c h}^{\prime \prime}\right)_{c r i t}=106 \sqrt{D} \mathrm{~kW} / \mathrm{m}^{2}$

Equation 12 can be used to obtain the maximum (equivalent) diameter for which sustained flaming is possible, given a measured peak heat release rate per unit area. This is shown in Table 5, where the length-scale of material that can anchor a flame appears to fall into two groups, greater than $1.5 \mathrm{~m}$ and less than $1.5 \mathrm{~m}$. A heat release rate criterion based on this length scale for sustained flaming may serve as a good indicator to support visual observations of flaming or the lack thereof during tests in the FPA with $40 \% \mathrm{O}_{2}$.

\section{CONCLUSIONS}

This study provides a scientific basis for rating materials as "noncombustible" by examining the requirements for sustained flaming of materials that have mostly inert components (i.e., are highly fuel dilute). It is concluded that combustibility criteria based on heat of combustion, either per unit mass of the virgin material or even per unit mass of the fuel vapors alone are not practical, especially for the very low values associated with these specimens. The temperature rise of a specimen in a furnace test method is also not a practical combustibility criterion because of the difficulty in relating the conditions of the small furnace specimen to actual fire scenarios. On the other hand, observations of the absence of sustained flaming on a horizontal specimen, supported by a measured peak heat release rate per unit area less than the critical value given by Eq. 12 for a $1-$ to $1.5-\mathrm{m}$ material length-scale is a reliable determinant of non-combustibility. This conclusion is consistent with the results of one-second-average heat release rate measurements on four prototype "noncombustible" materials in the FPA under conditions that promote combustion $\left(40 \% \mathrm{O}_{2}\right.$ concentration) and simulate the heat flux environment $\left(50 \mathrm{~kW} / \mathrm{m}^{2}\right)$ 
in real-scale fires. As an additional safety factor, a minimum residue mass fraction (e.g., $90 \%$ ) could be required for a "noncombustible" rating.

\section{ACKNOWLEDGMENTS}

The authors wish to thank Mr. Stephen P. D’Aniello and Mr. Stephen D. Ogden for performing laboratory FPA tests. This work is part of the Flammability Technology Research Program supported by FM Global.

\section{REFERENCES}

[1] ASTM D 5865, "Standard Test Method for Gross Calorific Value of Coal and Coke," Annual Book of ASTM Standards, Vol. 5.06, American Society for Testing and Materials, West Conshohocken, PA 19428, USA 1999.

[2] ISO 1716, "Reaction to Fire Tests for Building Products - Determination of the Gross Calorific Value," International Organization for Standardization, Geneva, Switzerland, 1999.

[3] ASTM E 136, "Standard Test Method for Behavior of Materials in a Vertical Tube Furnace at $750^{\circ} \mathrm{C}$," American Society for Testing and Materials, West Conshohocken, PA 19428, USA, 1999.

[4] ISO 1182, "Reaction to Fire Tests for Building Products - Non-Combustibility Test," International Organization for Standardization, Geneva, Switzerland, 1998.

[5] Ahonen, A., Weckman, H. and Yli-Penttila, M., "Application of Oxygen-Consumption Calorimetry to Non-Combustibility Testing," Fire and Materials 9: 135-144 (1985).

[6] Rasbash, D.J., Rogowski, Z.W. and Stark, G.W.V., "Properties of Fires of Liquids," Fuel, 31: 94-107 (1956)

[7] Tewarson, A., "Generation of Heat and Chemical Compounds in Fires," The SFPE Handbook of Fire Protection Engineering ( $3^{\text {rd }}$ ed), DiNenno P.J. (ed), National Fire Protection Association, Quincy, MA, 02269, USA, 2002, pp. 3-102 to 3-117.

[8] ASTM D 5630, "Standard Test Method for Ash Content in Thermoplastics," American Society for Testing and Materials, West Conshohocken, PA 19428, USA, 1994.

[9] Deepak, D. and Drysdale, D.D., "Flammability of Solids: An Apparatus to Measure the Critical Mass Flux at the Firepoint," Fire Safety Journal 5: 167-169 (1983).

[10] Wood, B.D., Blackshear, P.L.Jr. and Eckert, E.R.G., "Mass Fire Model: An Experimental Study of the Heat Transfer to Liquid Fuel Burning from a Sand-Filled Pan Burner," Combustion Science and Technology 4: 113-129 (1971).

[11] Heskestad, G., “A Reduced-Scale Mass Fire Experiment," Combustion and Flame 83: 293-301 (1991).

[12] ASTM E 2058, "Standard Test Methods for Measurement of Synthetic Polymer Material Flammability Using a Fire Propagation Apparatus (FPA)," American Society for Testing and Materials, 2002.

[13] Tewarson, A., Lee, J.L. and Pion, R.F., "Influence of Oxygen Concentration on Fuel Parameters for Fire Modeling," Eighteenth Symposium (International) on Combustion, The Combustion Institute, Pittsburgh, PA, USA, 1981, pp. 563-570.

[14] Gandhi, S., "Study of Advanced Fire-Resistant Materials for Aircraft Applications," Proceedings of the Third International Conference on Fire Research and Engineering, Society of Fire Protection Engineers, Bethesda, MD, 1999, p.196.

[15] ASTM E 1354-97, "Standard Test Method for Heat and Visible Smoke Release Rates for Materials and Products Using an Oxygen Consumption Calorimeter," American Society for Testing and Materials, West Conshohocken, PA 19428, USA, 1997.

[16] PrEN 13501-1, "Fire Classification of Construction Products and Building Elements - Part 1: Classification Using Test Data from Reaction to Fire Tests," European Committee for Standardization, rue de Stassart 36, B-1050 Brussels, Belgium, September 2000.

[17] de Ris, J.L. and Khan, M.M., "A Sample Holder for Determining Material Properties," Fire and Materials 24: 219-226 (2000). 